\title{
Creating a Facility for Developing Professional Skills
}

\author{
McCowan, J.D. and Mason, J.L. \\ Faculty of Applied Science, Queen's University \\ Kingston, Ontario, Canada
}

There is almost universal agreement that an effective engineer must possess a broad range of professional skills, extending far beyond the technical expertise of his or her discipline. An engineer also requires a sensitivity to societal needs, to the environment, and to other individuals, if he or she is to practise in an ethical and responsible way. An effective engineer must command not only the theory relevant to his or her area of engineering, but also the skills and attitudes necessary for the successful elevation of theory to practice.

At Queen's University, the Faculty has embarked on a major curriculum reform designed to improve the professional skills of our graduates. These include communication skills in a wide variety of situations, team skills, design skills, and lifelong learning skills. And while continuing to educate people in particular disciplines, we intend to make all engineering students more aware of the expertise of engineers in other disciplines.

A second objective is to develop ethical standards, environmental and cultural awareness, and a sense of social responsibility, all of which we think necessary for the highest level of professional practice.

Finally, we seek to broaden the range of learning methods so as to accommodate a broader range of learning preferences. We want more active learning, to improve the depth and the retention of student understanding of theory.

The techniques chosen to address these needs include a significant increase in team-based, project-based learning, increased design content, generating more active learning through immediate application, and a conscious use of the building environment as a teaching tool. We have already introduced new courses to address many of these issues, notable a team-based first year project course, running through both terms. This course, and an associated course in aspects of professional practice, form a key introduction to the new program, known as Integrated Learning. However we have found ourselves limited by our existing facilities, and have embarked on construction of a new building containing new types of learning space, the Integrated Learning Centre.

In designing facilities to support expansions in these areas, we have examined facilities in

"Proceedings of the 2002 American Society for Engineering Education Annual Conference \& Exposition Copyright (02002, American Society for Engineering Education" 
several universities. We have found that most engineering schools have addressed these problems to some degree and most have some successes from which we could learn. However four or five have been particularly valuable to us. For the benefit of those of you interested in introducing changes of this nature, we include a few words on each.

Aalborg University in Denmark was formed in 1974 and from the beginning has used team-based, project-based learning in all years of all programs, including programs in the humanities and the social sciences. ${ }^{1}$ The campus is designed explicitly to support this approach. Every student in every year is part of a team with a permanent team office. The consistent emphasis on the development of team skills, and the utilization of project-based learning, are exemplary. Aalborg features many novel approaches, and has a substantial staff devoted to improving teaching and to evaluating educational approaches. One of their most novel features is the extent to which control of the undergraduate budget is in the hands of elected study boards, comprised equally of staff and students. Links to industry are extremely well developed, including a large number of industrial engineers resident on campus, most of whom are associated with the NOVI Science Park.

Whereas Aalborg began with a green field and a radical mandate, the engineering school in the University of Colorado at Boulder in the United States was faced with creating facilities to support new approaches to learning within the context of entrenched departments and an established culture. ${ }^{2} 3$ Change was confined to the engineering Faculty, and any faculty-wide initiatives were seen by those with strong departmental orientations as competition for scarce funds. Our own situation is much more like that at Colorado than it is like that at Aalborg, and so Colorado has been a valuable model for us. Their specific contribution was the creation of a novel central facility to support all undergraduate engineering programs. It includes several types of learning space which have proven to be effective and versatile. It also utilizes building elements in the teaching program, and supports an outreach program to high schools.

Rensselaer Polytechnic Institute in New York State has pioneered the studio approach to both science and engineering. There has been a succession of developments there, with the current state-of-the-art being circular and semi-circular, bi-directional studios in engineering. ${ }^{4}$ Rensselaer has made excellent use of large team projects to which any given team contributes a term of work, including a succession of manned gliders. Rensselaer has also developed a multidisciplinary design and manufacture facility ${ }^{5}$.

Other U.S. universities which have programs and facilities which influenced us to some degree were Drexel University (computer based teaching groups developing communication and team skills and computer literacy), the Massachusetts Institute of Technology (integrated and multidisciplinary approach to design, manufacture and testing in aerospace $)^{6}$ Ohio State University (design projects in year one), University of Pittsburgh (where the Chemical and Petroleum Engineering Department developed a computer laboratory with great skill and insight $^{7}$ ), and Stanford University (a course in learning design through mechanical dissection ${ }^{8}$ ).

The Mechanical Engineering program at the Université de Sherbrooke in Canada has made

"Proceedings of the 2002 American Society for Engineering Education Annual Conference \& Exposition Copyright (O2002, American Society for Engineering Education" 
very significant and effective changes in its program. ${ }^{9}$ These include the use of design projects extending over more than one year, strong interaction with industry, and incorporation of non-engineers in the design teams. Sherbrooke has also been innovative and successful in accelerating the development of a professional culture, and in utilizing novel assessment techniques to improve learning.

Australian engineering schools have been highly innovative in undergraduate engineering. One which has been instructive for us is the University of Melbourne which developed effective team-based learning for year one students with each team led by a senior undergraduate. Melbourne also created an academic Chair for a senior engineer with a distinguished record of practice and no academic experience.

\section{The Facilities of the ILC}

Floor plans, some renderings, and a great deal of information about the building may be found on the web site at http://ilc.queensu.ca/News/gallery.shtml. What follows is a summary of the major features.

\section{(a) teaching studio}

The studio approach has been the norm in schools of architecture, where the teaching of theory and its application to design have long been well integrated. While most institutions will have examples of such teaching in engineering, few have pursued the issue as consciously as Rensselaer Polytechnic Institute. A progression of studio types has led to circular and semicircular designs in which the students slip back and forth between a lecture mode, facing inward, and an application mode, facing outward.

One such studio, accommodating up to 76 students, is included in the ILC. Facing inward, the student views a monitor on which the instructor can show any material. An instructor located in front of all of the students can lecture, using the flat screen monitors to show close-up views or other material. Facing outward, the student has access to a computer and, where required, equipment for constructing components, performing tests, simulating equipment or any other activity which requires the student to apply immediately the theory learned in the lecture.

Finally, it is not irrelevant that the space containing the teaching studio (as with the design studio and the active learning centre) is curved and a bit unusual. It is shaped intentionally to create an expectation of change and innovation. If one wishes students to "think outside the box", it is perhaps not advantageous to locate them in a box.

\section{(b) first year studio}

The first year curriculum is common to all programs. Some 600 students are currently registered each year. Since the introduction of Integrated Learning, all take a course, APSC 100, which includes a team-based design project component. The course may draw on any portions of the year one material in each project, and often requires the student to learn new material on their own. A few lectures are included at the beginning on teamwork issues.

The nature of projects currently undertaken is limited by the facilities available. The first year studios in the ILC are intended to relieve this restriction, providing an excellent location for a great variety of projects. Modelled after similar spaces at the University of Colorado at Boulder,

\section{"Proceedings of the 2002 American Society for Engineering Education Annual Conference \& Exposition Copyright (O2002, American Society for Engineering Education"}


each studio accommodates 36 students. Each has facilities for a variety of activities: tables and chairs, benches, hand tools, storage lockers, a few computers, whiteboard and projection equipment. Such rooms allows an instructor and teaching assistants to work with students engaged in various projects.

\section{(c) design studio and prototyping shop}

Design studios and prototyping/manufacturing facilities are common enough in engineering schools, but they are often associated with one particular program or department. The ILC contains a studio available for multidisciplinary usage, as in the Multidisciplinary Design Laboratory at Rensselaer.

The associated prototyping facility is similarly multidisciplinary, with a mill, lathe and other machine tools, printed circuit manufacturing capability, a "rapid prototyper" and other tools. These facilities allow the prototyping of a certain proportion of design projects from courses in any year. They also assist in supporting the teams participating in various international and national competitions: solar car, mini-Baja, SAE Formula Car, concrete canoe, concrete toboggan, and various aero and robotics teams..

\section{(d) instrumented plazas}

The building incorporates "plazas" of "instrumented benches", with each bench containing a certain set of equipment and accommodating up to four students. Activities from different courses, different years, and different programs can be undertaken at these benches. Equipment specific to any particular activity is stored and can be collected by the students from one of the storage areas when required, and returned there when that activity is complete.

There are also two specialized plazas, one accommodating chemically based projects requiring special ventilation and one accommodating electrical projects with high power requirements.

Data obtained from the benches are stored centrally and can be recovered through the web in residence, in other engineering buildings, or indeed anywhere with web access. The main plazas will be open to students at all times where there is sufficient use to justify it. Such usage patterns have two major benefits. First, they remove the artificial constraint of a two- or three-hour laboratory slot, allowing longer and more complex activities, allowing different students to move at different paces, and allowing students to repeat or vary measurements if they wish. Secondly, they allow for intense use of space and equipment, by functioning in the evenings and on weekends.

\section{(e) active learning centre}

Many schools have such a classroom. It incorporates individual chairs and tables for each student. These can be quickly reconfigured, even during the midst of a class, to switch from lecture (where the arrangement can be circular, semicircular, rows or whatever the instructor prefers) to discussion or project activity, where each group of students push their tables together and work as a team. There are whiteboards and projection capability at both ends of the room.

\section{(f) site investigation facility}

Students conducting field work return to the university with samples of rock, soil or water which must be analyzed and studied. Many aspects of that analysis inevitably occur in specialized

\section{"Proceedings of the 2002 American Society for Engineering Education Annual Conference \& Exposition Copyright (O2002, American Society for Engineering Education"}


facilities primarily devoted to research. There is a need, however, for a facility accessible to undergraduates in which they can carry out the initial processing of their samples, perform some types of analysis, and gain access to data banks relevant to their needs. All of this is provided in a "site investigation facility", located near a loading bay and accessible at any hour.

\section{(g) competitive team space}

Many students participate in international competitions for engineering projects. Various robotic devices, various kinds of vehicles (from solar cars to concrete canoes) and other engineered devices form the basis for such competitions. Although these events typically take place partially or entirely outside of the curriculum, they are excellent examples of team-based, project-based learning. They are also highly motivating, both to participants and to observers.

A suite of rooms has been provided to support such team activities. A complex of rooms is provided in which the rooms can be used singly or in combination by different teams, and all have access to some common areas devoted to teams (such as a well vented room for painting and the like) as well as to all of the other building facilities, including the prototyping shop.

\section{(h) group rooms}

Team-based, project-based learning requires students to meet as teams to search for solutions to their problems, discuss alternatives, consider results, and prepare written and verbal presentations. Most universities provide some spaces suitable for these activities, with Aalborg University being outstanding in this regard. Aalborg provides a permanent office for every team in every year of every program, about 1500 offices in all.

At Queen's, there are already 150 teams associated with year one, and Integrated Learning involves a significant increase in team-based activities. Hence over forty additional team meeting rooms are provided. About one third accommodate teams of up to twelve people, and the remainder serve teams up to six. Furnishings are simply a boardroom table, chairs, and computer connections. These rooms will be available during most hours of the day, seven days a week.

\section{"Live Building"}

In designing the building, provision has been made to utilize the building's own structure and functions in the learning program. At its simplest level, this involves web pages and/or signage explaining the function of particular building elements. However much more can be done if data are collected on building parameters. All large buildings involve the monitoring of certain building parameters in order to operate the HVAC system, the power system, and so on, and some recent buildings monitor performance for educational purposes. The United States Department of Energy, for example, advocates both energy efficient schools and utilization of building data within the school program ${ }^{10}$. The ITLL at the University of Colorado at Boulder uses the "Building as a Learning Tool"11

"Proceedings of the 2002 American Society for Engineering Education Annual Conference \& Exposition Copyright (02002, American Society for Engineering Education" 
The ILC incorporates an extensive system of sensors to monitor structural, electrical and mechanical elements. In a few cases, technologies have been chosen in part for their educational value. A photovoltaic array and a fuel cell are included, even although each makes a relatively small contribution to the electricity requirements of such a large building. However both are important technologies that we wish to make available to students.

All data will be on the net, available to be used by students in other engineering schools, in outreach programs to schools, and by architects and engineers interested in some of the performance data.

\section{Green Building}

Since the building technology will be used as part of our teaching, the choice of the technology is important. This has influenced us in several ways, but particularly in introducing green features. Most of these are standard: high quality windows, maximal use of natural light, use of computer screens with low energy requirements. Others are less common: a green wall to help purify internal air, a minimum energy ventilation system, wider-than-usual temperature limits, retention of rainwater for building use, and an intelligent lighting system. The performance of most or all of these elements will be monitored as part of the live building, and the data will be made available on the net. In addition, data from some green technologies which could not be found on campus will be monitored at remote sights and included. These include a large wind generator and a run-of-water generator. As with other live building data, this information will be available for use by undergraduates at Queen's or elsewhere, in outreach programs, or by the public generally.

\section{Summary}

A new building, involving 6500 square metres of new space, will be constructed beginning in the summer of 2002. The building allows the Faculty of Applied Science to provide more active learning, to develop the professional skills of its students, and to experiment with various means of doing both. Opening is planned for January 2004.

\section{References}

1.F. Kjersdam and S. Enemark, "The Aalborg Experiment", Aalborg University Press, 1994 2.L.E. Carlson and J.F. Sullivan, "Hands-on Engineering: Learning by Doing in the Integrated Teaching and Learning Program", International Journal of Engineering Education 15, 20 (1999)

3. http://itll.colorado.edu/ITLLweb/Home/Home.cfm?TopCategoryID=1

4. http://www.rpi.edu/dept/cis/IntelProject/Projects/corestudiophotos.html

5. http://www.eng.rpi.edu/News/s01_mdl.htm\#article

6. http://web.mit.edu/aeroastro/www/about/facilities/learninglaboratory.html

7. http://www.engr.pitt.edu/chemical/fmlc/webpa_1.htm

8. http://www-adl.stanford.edu/images/dissphil.pdf

9.D. Proulx, M. Brouillette, F. Charron and J. Nicolas, "A New Competency-Based Program for

"Proceedings of the 2002 American Society for Engineering Education Annual Conference \& Exposition Copyright (02002, American Society for Engineering Education" 
Mechanical Engineers", Canadian Society of Mechanical Engineers Forum, Toronto, (1998)

10. http://www.eesi.org/publications/09.23.99smartschools.pdf

11. http://itll.colorado.edu/ITLLweb/BuildingData/BuildingData.cfm?TopCategoryID=9 